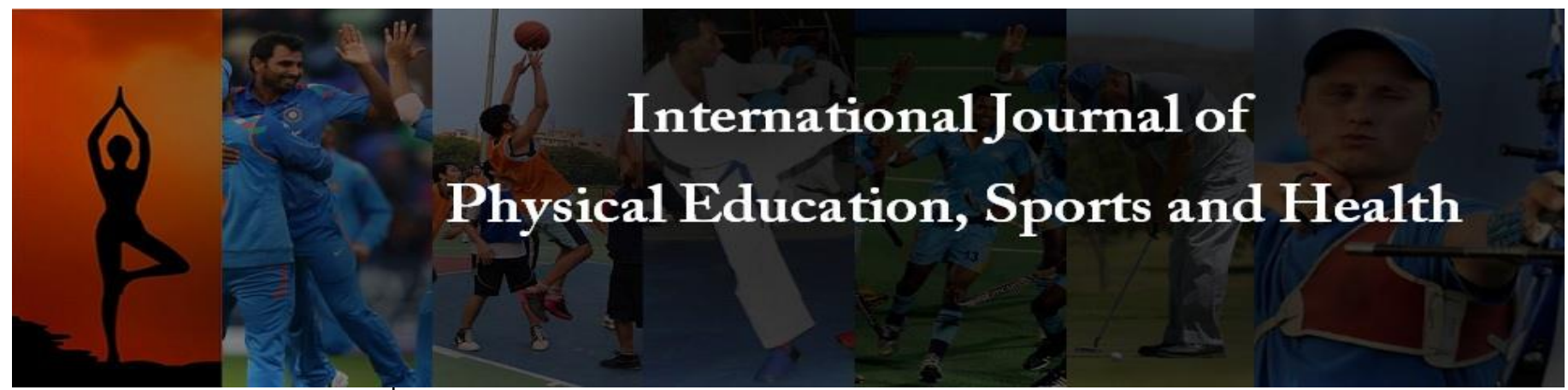

P-ISSN: 2394-1685

E-ISSN: 2394-1693

Impact Factor (ISRA): 5.38

IJPESH 2021; 8(3): 19-21

(C) 2021 IJPESH

www.kheljournal.com

Received: 15-03-2021

Accepted: 20-04-2021

\section{Nitesh Karkhu}

Ph.D. Research Scholar,

Department of Physical

Education, Swami Vivekanand

Subharti University, Meerut,

Uttar Pradesh, India

\section{Dr. Sandeep Kumar}

Professor and Head, Department of Physical Education, Swami

Vivekanand Subharti

University, Meerut, Uttar

Pradesh, India
Corresponding Author: Dr. Sandeep Kumar

Professor and Head, Department of Physical Education, Swami

Vivekanand Subharti

University, Meerut, Uttar

Pradesh, India

\section{A study of sports achievement and sports personnels of government and private schools belongs to national capital region: A comparative study}

\section{Nitesh Karkhur and Dr. Sandeep Kumar}

DOI: https://doi.org/10.22271/kheljournal.2021.v8.i3a.2055

\begin{abstract}
The purpose of study was to compare the sports achievement \& sports personnel between government and private schools situated in the NCR, Delhi. In this study fifty schools of NCR were selected (25 Govt $\& 25$ Pvt) through random sampling. For the purpose of the study the data have been collected through self-developed data sheet containing all required information and same has been collected with the help of google sheet. After collection of data, the descriptive statistics and t- test (Independent) was applied for the analysis of data. The result of the present study was found that there was significant difference in the sports achievement and Sports Personnel between the government and private schools. The study shows that the sports achievement and sports personnel of private schools found better in comparison of government schools of National Capital Region.
\end{abstract}

Keywords: Sports achievement, sports personnels', government schools, private schools, national capital region

\section{Introduction \\ Sports Personnels}

The role of physical education personnel in the society is important. Physical education personnel are the architect of the future sportsman and backbone of physical education programme in educational institutions. They can make the physical education programme successful and effective by their leadership qualities. Physical education personnel's plan and direct the programme for effective implementation. Students show interest when they work under competent Physical education personnel.

Today, Physical Education teachers are playing a number of diverse as well as specialized roles as teachers, officials, organizers and administrators. A physical education teacher should be a good planner in the sense that he must understand the objectives of physical education and design a programme that fits into the total educational programmes. He/she should also compare the objectives to the local needs or the area of Physical Education in which the students are weak or are interested in improving themselves.

The responsibilities of Physical Education teacher have increased manifolds in modern scientific age. The expectations of the society and nation towards Physical Education teachers are very high in the sense that they are the only leaders who can protect and save the general fitness of the sedentary people in the machine age. The rise of sports science such as Physiology, Sports Psychology, Sports Sociology, Kinesiology, Biomechanics has further added to the already enhanced scope of the duties of Physical Education teachers. The qualities, traits and characteristics of personality and character of the Physical Education teachers, by and large, are abstract concepts. Prescribing norms and objective standards on this account is but impossible. Only academic and professional qualifications - not even competencies - can be desirably listed out so that one could adhere to their prescribed standards. From an idealistic point of view, a Physical Education teacher ought to have commitment to the profession, alertness of body and mind, adjustability, initiative, fitness for 
work, discipline, enthusiasm, sincerity, self-control, sociability, super motor capacity, sense of humor, honor, dignity, self-confidence, impartiality, communicative skills, sportsman's spirit etc. He must be a model for his students and colleagues with regard to his character, conduct and behavior (Kamlesh, 2002).

With the change in the concept of Physical Education, the role of the Physical Education teacher has gone beyond the playground and entered the classroom teaching. It is perhaps far more important for a physical education teacher to concentrate upon success factors rather than think about failures in order to achieve proper results. In order to meet the high standards of the profession, Physical Education teachers must take advantage of all the information available to them about the students. This includes the characteristics and needs of the pupils, the facilities and tools with which they may work, organizational and administrative factors that affect the programme and knowledge of the subject matter and activities they are going to undertake.

Physical Education is neither a business nor an industry; it is a field of education where the inter-personal interaction is better understood as a means of socialization process than a trade transaction. In its multi-dimensional perspective, Physical Education is -a programme of activity, an instructional process, a field of organization and administration and an area of research and development. Accordingly, a Physical Education teacher has to use the skills and aptitudes for a business-like approach to "man, movement, mind and material" and there are neither short cuts nor compromise on quality, competence and efficiency of those involved. But unfortunately, in proportion to the expectations of the society, the Physical Education teachers have not been given due place and recognition. They face a lot of problems while carrying out their responsibilities. Bad working conditions, ill maintained playgrounds, lack of facilities create obstacles and hurdles in their efficient and smooth functioning. The Indian teachers today operate in an environment full of uncertainties, turbulence and even hostility.

\section{Sports Achievement}

To enhance the image of the nation, the games and sports activities either on competitive level or on recreational level is becoming an essential at National and International level. Games are also very helpful in developing character building, international friendship and mutual understanding for health to lead a healthy and happy life. Therefore, promoting the program related with physical education and sports, and creating the sports environment among the society should be the prime task of policy makers and executers. To get the fame at International level, it is essential to provide the high standard of coaching and facilitation of good equipment and diet. The favorable environmental factors of suitable facilities and coaching plays an important role in shaping up the growth of players' personality. The level of participation and achievement, either single or combined, through interaction with each other always give the satisfactory results towards sports achievement. The ambiguity in appointment, dissatisfaction and eventually the crumbling of individual character and increase in physiological working, one necessity either a changed method of activity which may bring about the fulfilment of some need or want. It is called attention to by instructors and clinicians that generally people learn and develop by communication impersonation and perception. This can be efficient or unsystematic. In any case, the ecological elements of appropriate offices and instructing do assume a predominant job in getting down to business the development of the character, level of accomplishment, either single or group, through communication with one another. In the event that the climate is amicable and program is well through the development might be fullest, in this way, high accomplishment, else it could be hampered.

\section{Material and Method}

The objective of study was to compare the Sports Achievement \& Sports personnel between Government and Private Schools of National Capital Region and it was hypothesized that there is no significant difference in Sports Achievement \& Sports personnel between Government and Private Schools of National Capital Region.

For the present study 50 senior secondary schools (25 Government and 25 Private) of National Capital Region were selected by using random sampling. The data was collected as per the nature of descriptive study based on static group comparison design through self-prepared data sheet. The sports achievement and available sports personnel's' details were collected in the duration of last three academic years.

For the analysis of collected data, the descriptive statistics was applied and to compare the sports achievement \& personnels' between the government and private schools of National Capital Region, the t-test was applied. The level of significance was set at the 0.05 .

\section{Analysis and Discussion}

Table 1: Comparison of Sports Achievement between Government and Private Schools

\begin{tabular}{|l|c|c|c|c|c|}
\hline \multirow{3}{*}{ Sports Achievement } & Category & N & Mean & S.D. & t-ratio \\
\cline { 2 - 5 } & Government Schools & 25 & 27.04 & 36.06 & \multirow{2}{*}{1.84} \\
\cline { 2 - 4 } & Private Schools & 25 & 54.84 & 66.25 & \\
\hline
\end{tabular}

*Level of significance at 0.05 , df- 48 , table value - 1.68

Table -1 shows the average score of Sports Achievement between Government and Private schools of National Capital Region i.e., $27.04 \& 54.84$ respectively. The table shows the significant difference in Sports Achievement between the Government and Private schools, as the t-ratio 1.84 was found higher than the required table value 1.68 at 0.05 level of significance.

It shows that the Sports Achievement of Private Schools was found higher in comparison to Government Schools. The graphical representation of Comparison of Sports Achievement between Government and Private Schools is presented in Figure-1.

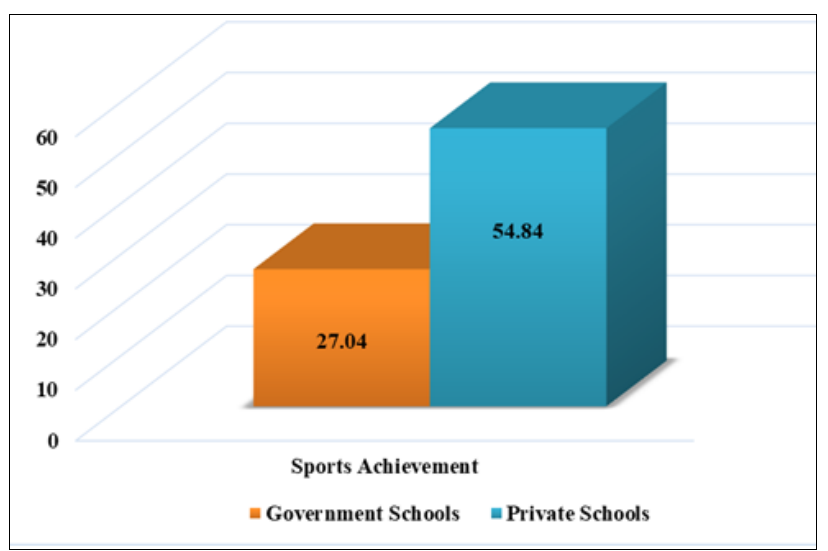

Fig 1: It shows that the Sports Achievement of Private Schools was found higher in comparison to Government Schools 
Table 2: Comparison of Sports Personnel's Between Government and Private Schools

\begin{tabular}{|l|c|c|c|c|c|}
\hline \multirow{3}{*}{ Sports Personnel's } & Category & N & Mean & S.D. & T-Ratio \\
\cline { 2 - 5 } & Government Schools & 25 & 10.12 & 6.78 & \multirow{2}{*}{4.95} \\
\cline { 2 - 5 } & Private Schools & 25 & 23.28 & 11.40 & \\
\hline
\end{tabular}

*level of significance is at 0.05 , df- 48 , table value -1.68

Table -2 shows the average score of Sports Personnels' between Government and Private schools of National Capital Region i.e., $10.12 \& 23.28$ respectively. The table shows the significant difference in Sports Personnels' between the Government and Private schools, as the t-ratio 4.95 was found higher than the required table value 1.68 at 0.05 level of significance.

It also shows that the scores of Sports Personnels' of Private Schools were found higher in comparison to Government Schools. The graphical representation of Comparison of Sports Personnels' between Government and Private Schools is presented in Figure-2.

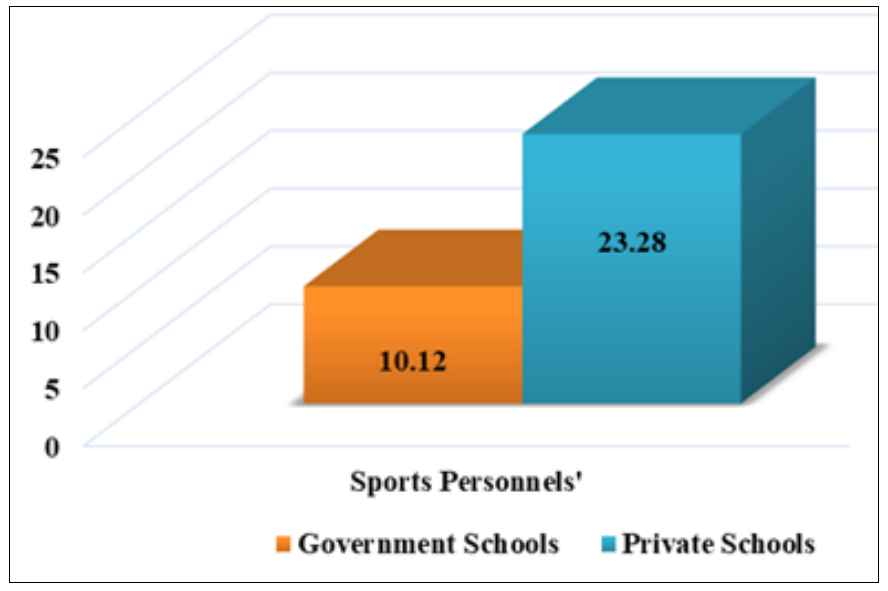

Fig 2: It also shows that the scores of Sports Personnels' of Private Schools were found higher in comparison to Government Schools

\section{Result of the Study}

The analysis of the study shows that the Government and Private schools situated in National Capital Region had a significant difference in Sports Achievement and Sports Personnels'. The reason behind this that the availability of sports personnels' to achieve the sports achievement in Government Schools may be adequate as per the laid down norms and standard but there may be a lacking of utilization of them and the proper execution and guidance not reaching the students. However, in this competitive era of privatization of education, the private schools providing more facilities in term of appointing the Sports Personnels' and developing the high standard sports facilities. The students also using properly the available facilities under the guidance of skilled professionals.

\section{References}

1. Thakur BS, Mohan L. "Personality Traits, Anxiety and Achievement Motivation Level of Volleyball Players and NonSpotmen", Journal of Sports and Sports Sciences 2008;31(4):23-29.

2. Singh CP, Ahmed M, Hussain I. "A Comparative Study of Sports Achievement Motivation between Male and Female Badminton Players" Vyayam-Vidnyan 2010;43(3):30-33.

www.bjsm.bmj.com/content/44/supplement_1

3. Dureha DK, Singh M, Yaduvanshiand S, Mishra P. "A
Comparative Study of Incentive Motivation and Anxiety Level between National and International Hockey Players" British Journal of Sports Medicine 2010;44(1):58.

4. Dalwinder S, Sonia S. Sports achievement motivation among wrestlers and judokas-a comparative study. International Journal of Behavioural Social and Movement Science 2013;2(1):70-75.

5. Domuschieva- Rogleva G. Determinant of sport motivation with wrestling athletes. Research in Kinesiology 2015;43(1):94-98.

6. Elliot and McGregor "Test anxiety and the hierarchical model of approach and avoidance achievement motivation". Journal of Personality and Social Psychology 1999;76:628-644.

7. Kaur K, Sharma NP, Dureha DK. "Relationship between Achievement Motivation and Pre-Competition Anxiety of Indian Inter University Hockey Players" Scientific Journal in Sports and Exercise 2007;3(2):24-26.

8. Kumar MR. Effect of Urban-Rural Belongingness on Mental Toughness of National Male Judo Players. Journal of Sports Sciences 2011;2:4.

9. M.L. Kamlesh, "Educational Sports Psychology". (New Delhi-Friends Publication, 2006.

10. Kamlesh ML. "Educational Sports Psychology". (New Delhi-Friends Publication, 2006).

11. Kamlesh ML. "Sports Achievement Motivation Test"http//Shodhaganga. Inflibnet.ac.in /10603/2737/12/12 - chapter 3. 1990

12. Kamlesh ML. Foundations of Physical Education, (New Delhi: Metropolitan Book Co. Pvt. Ltd.), 183-185.

13. Robert Glyn C. "Achievement Motivation in sports". Department of Physical Education. University of Iltinous.

14. Tammy A. Schilling. "Achievement motivation: Conceptions of ability, subjective experience, task choice, and performance". Canadian journal of sports Psychology 2001;91:338-246.

15. Khan Z, Khan S, Ahmad N. "Sports Achievement Motivation among Asian Players" AMASS Multilateral Research Journal 2010;2(2):7-9. 